\title{
Partial-factor Energy Efficiency Model of Indonesia
}

\author{
Fathul Nugroho ${ }^{1}$, and Noor Syaifudin ${ }^{2,3, *}$ \\ ${ }^{1}$ The Future Institute, Jl. Dukuh Patra V No.48, Kuningan, Jakarta 12950, Indonesia \\ ${ }^{2}$ UWA Business School, Business School Building, Crawley Campus The University of Western \\ Australia, 35 Stirling Highway Crawley WA 6009 Perth, Australia \\ ${ }^{3}$ Fiscal Policy Agency, Ministry of Finance of Republic of Indonesia,Notohamiprodjo Building, $1^{\text {st }}$ \\ Floor, Jl. Wahidin No 1, Senen, Jakarta, 10710, Indonesia
}

\begin{abstract}
This study employs the partial-factor energy efficiency to reveal the relationships between energy efficiency and the consumption of both, the renewable energy and non-renewable energy in Indonesia. The findings confirm that consumption of non-renewable energy will increase the inefficiency in energy consumption. On the other side, the use of renewable energy will increase the energy efficiency in Indonesia. As the result, the Government of Indonesia may address this issue by providing more support to the development and the consumption of renewable energy in order to increase the energy efficiency and vise versa.
\end{abstract}

Key words: Energy efficiency, renewable energy, partial effect model

\section{Introduction}

There are several literatures and studies on the energy efficiency in Indonesia. Among others, the study by Syaifudin et al. revealed that the fiscal transfer signals a positive impact to the energy efficiency in Indonesia [1]. Setyawan viewed that revolving fund scheme is necessary to improve energy efficiency projects in Indonesia [2]. Moreover, Rajbhandari and Zhang argued that energy efficiency may significantly improve the economic growth of a country [3]. They summarized that in the middle-income countries, there was a long-run bidirectional causality between lower energy intensity and higher economic growth.

Thus, the Government of Indonesia (GOI) should adopt some policies to increase its energy efficiency. Domac et al. argued that bio-energy could contribute to the improvement of energy efficiency [4]. They further argued that the production and the use of bio-energy will create employment and economic return in most economies. In the macro-economic level, the production and the use of renewable energy such as bio-fuels, geothermal, solar, etc. to replace fossil fuels will contribute to all important elements of the economy. Generally, the increasing use of renewable energy will result in improvement in regional productivity, enhanced competitiveness, as well as further investment in resources to accommodate the economic development.

\footnotetext{
*Corresponding author: soib2007@gmail.com
} 
According to the Ministry of Energy and Mineral Resources, in 2015, renewable energy was ranked fourth source in terms of power generation capacity in Indonesia. The proportion of oil as an energy source was accounted for $43 \%$, followed by natural gas at 22 $\%$, coal at $28.7 \%$, and renewable energy at $6.2 \%$ (Figure 1 ). It was targeted that by 2025 the proportion of the new and renewable energy will be increased to $23 \%$ while the energy from oil is expected to reduce by $35 \%$ (Figure 2 ).

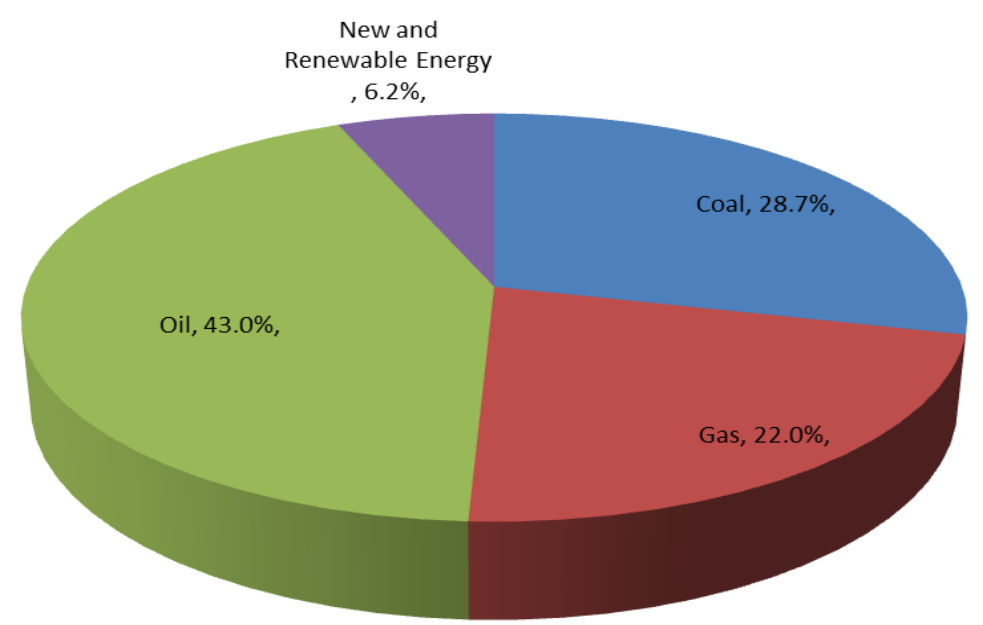

Fig. 1. Primary energy mix in 2015 [5].

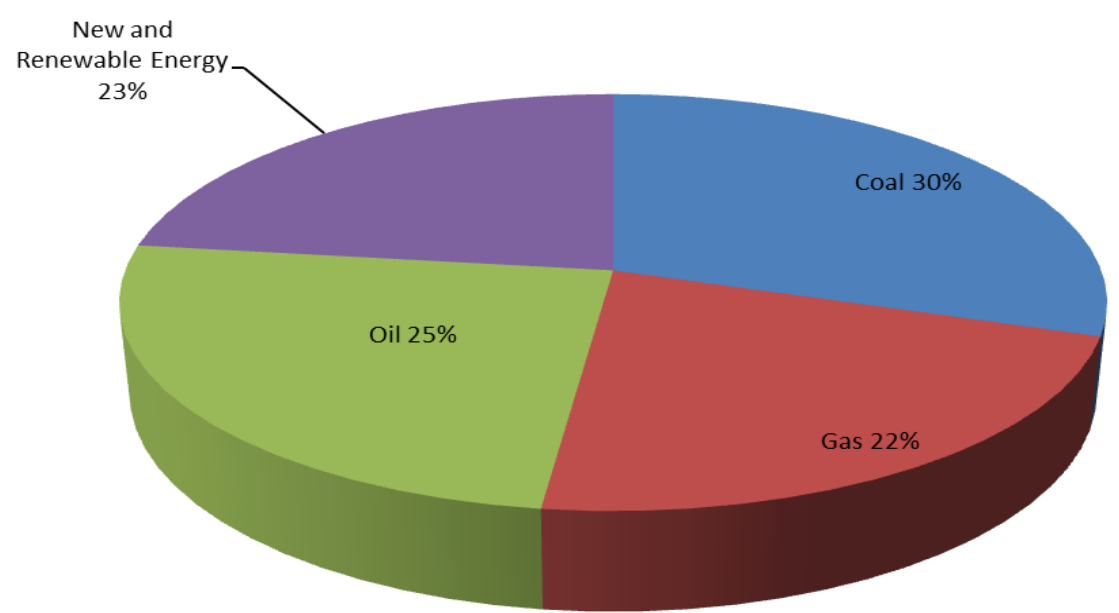

Fig. 2. Targeted primary energy mix in 2025 [6]. 
Chien and $\mathrm{Hu}$ have found a direct linkage between renewable energy and energy efficiency [7]. They verified that an increase in the percentage of renewable energy among total primary energy supply (TPES) improves energy efficiency. It is worth noting that increasing the input of renewable energy increases energy efficiency. In addition, renewable energy also has a great prospect to be a part of global energy sustainability. Currently, renewable energy is promoted to play a greater role in addressing climate change and increasing energy demand. Many nations are adopting policies to promote the use of renewable energy. Therefore, it is important for Indonesia to improve its energy efficiency by substituting fossil fuels energy with renewable energy.

Studies on energy efficiency are quite compelling among scholars nowadays. Among others are Krarti et al. who found that a large-scale energy efficiency program on buildings in Qatar may reduce about $11000 \mathrm{GWh}$ per y of the energy consumption [8]. Moreover, if the energy efficiency program is applied for more than $10 \mathrm{y}$, it can be potentially reducing more than 5.4 Mt of carbon emissions annually and may creates over 4000 jobs yearly. While the similar program is implemented in Egypt, the program can enhance the energy efficiency by $33 \%$ on average [9]. Li and Lin revealed that energy price reforms will lead to energy efficiency in China [10]. One of such technology that may be adopted is the capital embodied technological progress.

Otherwise, Trotta [11] and Ahmed and Stater [12] recommended stricter low energy regulation which may leads households energy efficiency as the result of the changing in the dwellers' behaviour towards the energy consumption. In the application in UK and Wales, Wang and Wang suggested that instead of reducing the energy consumption by $10 \%$, the energy efficiency application also supports the water sustainability [13]. The program will save the freshwater withdrawals by $0.43 \%$ of total public water supply and may supports around 138460 households.

However, improving energy efficiency by substituting primary energy sources with renewable energy alone will be not enough. Since energy consumption is a substantial input for economic growth, it is also important to adjust energy consumption to maximize efficiency. As a result, it is desirable for the Indonesian economy to increase its GDP and to decrease its inputs in order to maximize its macro-economic efficiency.

According to Çelen, total factor productivity (TFP) determines the improvement of energy efficiency in Turkey [14]. The energy efficiency (EE) index is calculated as a proxy for analyzing energy efficiency of Indonesia's economy. The EE index comprises of labor, capital stock, energy (fossil fuels), and renewable energy which is as inputs and GDP as the output of production function. One of the aims of this study is to verify whether renewable energy contributes to energy efficiency improvement using a regression analysis with empirical data from 1980 to 2005. The TE data is computed using data envelopment analysis (DEA) that currently has been widely used by many academics and researchers.

\section{Energy efficiency issue}

The first important thing to do in discussing energy efficiency issue is to have a clear definition on the term of energy efficiency. Many scholars and institutions provide the definition of energy efficiency. The most well-known term of energy efficiency is the technical definition of it, which is the ratio of energy output over energy input. The technical definition of energy efficiency often uses to describe the efficiency of engines, machineries, or power plants. The European Parliament provided a general definition of energy efficiency, which is a ratio between an output of performance, service, goods or energy, and an input of energy [15]. Indeed, it is very difficult to have a single definition of energy efficiency across the world. However, this study uses the definitions of energy 
efficiency in terms of economic view. That is, energy efficiency is GDP divided by total primary energy supply and the efficiency of energy use to produce economic outputs [15].

Indeed, energy efficiency improvement becomes a major global issue currently, in particular among developed nations. Most developed countries have been focusing their energy sector development for improving energy efficiency and developing renewable energy. A study by Geller et al. shows that industrialized nations have become more energy efficient than it was $30 \mathrm{yr}$ ago [16]. These countries were successful in adopting several policies for improving the efficiency of their energy sectors. Empirically, they started to improve their energy efficiency since the oil price shock in the 1970s in order to reduce their dependence to oil supply. By adopting several energy efficiency policies, their energy intensity significantly was declining to an efficient level.

In over last three decades, major Organisation for Economic Co-operation and Development (OECD) countries like Japan, United Kingdom, United States, and Australia have cut their demand for energy significantly. These countries were able to cut their energy consumption as much as $49 \%$ than it was actually consumed in 1998. Their total primary energy supply (TPES) per unit of GDP has declined sharply as well. In other words, energy intensity in major OECD countries has significantly declined, it is worth nothing, but OECD countries could produce a unit of GDP with less primary energy supply compares to in 1970s. The implementation of high-energy efficient products, energy mix, and behavioral change has contributed to the decline of energy intensity of major OECD countries [16].

There are at least two motives for developed countries to start improving their energy efficiency. First, developed countries target to improve their energy security. Since the oil price shock in 1970 s, developed nations were much more aware to secure their supply of energy. In that time, most of industrialized economies relied on oil supply from the Organization of the Petroleum Exporting Countries (OPEC) countries, in particular from the Middle East countries. Thus, in order to reduce their dependence on oil supply from the Middle East, they responded in various ways: from conserving energy use, reducing the demand for oil, searching for alternatives energy, and restructuring their oil-intensive industry to more energy efficient industry.

In conserving energy, developed countries had promoted some policies that change their behavior and economic activities [16]. For instance, in the US, the Federal government enacted policies that limit the speed of automobiles at $24.5 \mathrm{~m} / \mathrm{s}$ and enforce daylight saving time. The Federal government also implemented Corporate Average Fuels Economy (CAFE) policy that imposed automakers to produce more fuel-efficient vehicles that should meet the standard of fuel consumption at $8.55 \mathrm{~L} /(100 \mathrm{~km})$. Developed nations also paid more attention to the invention and adoption of alternative energy sources such as solar, wind, and nuclear energy.

Second, developed countries intend to improve their macroeconomic efficiency. Through the implementation of energy efficient technology, developed economies have been reducing the amount of energy as input of economic production, while maximizing GDP as the output of the economy. They moved from energy-intensive industries to more efficient and productive industries such Japan that invests much on high-tech industries such electronics and automobiles.

Nowadays, energy efficiency improvement continues to become a central issue of energy sector development in developed countries. Huge investments have been allocated to promote further energy efficiency research and development. This initiative was also involving many experts and scholars to invent new efficient technologies, mostly in developed countries.

However, energy efficiency improvement has not become a crucial issue in many developing countries. They only focus to achieve high economic growth, without pay much 
attention to further develops their energy sector. That is why the demand for energy is increasing as their economies grow. In most cases, developing nations have used intensive input of energy, but produced less units of GDP. One plausible factor is that developing countries are still relying on energy-intensive industries. Most of industries in developing nations are using primary energy sources rather than secondary sources of energy. In addition, most of these industries are producing low value-added products.

China, however, has set an ambitious target to cut down its energy intensity by $20 \%$ or $4.36 \%$ per annum between 2006 and 2010 with 2005 data as the basis. Even though in 2006 China has failed to achieve this target, they continue to implement their energy efficiency programs [17]. Chinese government is trying to achieve high-energy efficiency target through implementation several policies such as: i) restructuring the current energy intensive mode to a non-energy intensive mode, ii) using more high quality sources of energy, iii) improving its current technologies, iv) using high quality raw materials, and 5) improving energy system management. The Chinese government is very strict in implementing those policies. For instance, Chinese government enacted a special policy to force the shutdown several energy-intensive industries [17].

\section{Energy efficiency and macroeconomic productivity}

A common indicator to measure the relationship between energy and economy is energy intensity. This indicator simply meant a ratio of the TPES and GDP annually. Energy intensity data can be easily downloaded and computed from various energy agencies such as EIA and IEA. World Development Indicators from the World Bank also provide statistical data on energy consumption and production of various sources of energy and economic indicators data that can be used to calculate energy intensity or efficiency.

Recently, however, more researchers and energy agencies are using energy efficiency indicator instead of energy intensity to measure and compare countries economic performance. As noted before, energy efficiency is nothing but an inverse measurement of energy intensity. Energy efficiency is useful to measure how efficient such an economy in using primary energy as inputs of production, the less input of energy and the high economic output the better is the economy. Hence, a country with high energy efficiency will experience some socio-economic and environmental benefits. Logically, this country could reduce its energy inputs in order to minimize total production costs. As a result, its output products will be more competitive in the global market.

For a fuel importer country, high energy efficiency level will minimize its cost for importing fuels as well as reduce its consumption and thus improve its net trade balance. High energy efficiency also indicates that a particular country is using advanced technologies for exploitation, production, and distribution [18]. Thus, it is desirable for a country to have high energy efficiency, since this will bring positive impacts to the economy and the environment as a whole. By setting high target of an improvement in energy efficiency, an economy starts to reduce its energy use through adopting highly efficient technologies, mixing its input of energy with clean and renewable energy, and cutting down current high fossil fuel consumptions by changing its behavior and economic structure.

\section{Energy efficiency data}

A study by Wei [18] applied Cobb-Douglas production function to analyze the impact of energy efficiency gains on economic output. The study counted energy, labor, and capital stock as inputs of production function and found that energy the energy efficiency gains 
always lead to higher output. Thus, the impact of energy efficiency on total output in the long term almost doubles than that in the short term. Hu and Kao [19] also mentioned that energy, labor, and capital stock are the key inputs to produce the economic output.

Data envelopment analysis (DEA) is employed to measure an efficiency frontier for Indonesian economy in each year. The macroeconomic energy efficiency is to seek how far the economy of Indonesia is from its efficiency frontier in that year. Currently, the DEA method has been widely used for measuring energy efficiency among scholars [7][14][21]. A key benefit of DEA method over other models is that this method takes into account the dynamic efficiency of multiple inputs and multiple outputs. This method is the best fit to measure the energy efficiency frontier of an economy by combining multiple inputs and outputs. This type of linear programming allows the user to choose between input orientation and output orientation methods. Input orientation method calculates energy efficiency by combining the multiple inputs while holding constant the multiple outputs. Meanwhile, the output orientation computes the variables by combining the multiple outputs while holding constant the multiple inputs.

There are some scholars who have been using the DEA methods in their study on energy efficiency such as Chien and Hu employed the DEA to measure macroeconomic productivity [7]. Zhou and Ang employed the DEA method to calculate energy efficiency by considering the undesirable output of the economy [20]. That is, they take into account $\mathrm{CO} 2$ emissions as the undesirable output within the framework of production function. They also employed several DEA type linear programming models for calculating macroeconomic energy efficiency. In addition, their models treat different energy sources as different inputs so that changes in energy mix could be accounted for evaluating energy efficiency.

This study applies output orientation DEA, with the aim of this orientation is to determine a potential GDP output with given capital stock, labor force, fossil fuel, renewable energy, and clean energy as its inputs if it operated efficiently as economy along the best practice frontier. Output orientation model is in line with neo-classical production functions defined as the maximum achievable output given input quantities [20].

\section{Partial-factor energy efficiency model}

This study employs double-log regression analysis model. This model is used due to the preliminary estimation suggests the logistic function would be the appropriate model. The double-log form is the common model to be used for analyzing such a functional form, which is non-linear in the variables, but linear in the coefficients. The regression equations are as follow:

\section{First model:}

$$
\operatorname{LnEE}=\beta 0+\beta 1 \operatorname{Ln} G D P+\beta 2 \operatorname{LnPC}+\beta 3 \operatorname{\beta LnNGC}+\beta 4 \operatorname{LnCC}+\beta 5 \backslash \operatorname{LnREC}+\beta 6 \operatorname{Ln} C F+
$$

\section{Second model:}

$$
L n E E=\beta 0+\beta 1 L n G D P+\beta 2 \operatorname{LnPC}+\beta 3 \operatorname{LnNGC}+\beta 4 \operatorname{LnCC}+\beta 5 \operatorname{LnREC}+\beta 6 \operatorname{LnCF}
$$




\section{Third model:}

$$
L n E E=\beta 0+\beta 1 \operatorname{LnGDP}+\beta 2 \operatorname{LnPC}+\beta 3 \operatorname{LnNGC}+\beta 4 \operatorname{LnCC}+\beta 5 \operatorname{Ln} R E C
$$

Where EE is energy efficiency, GDP gross domestic products, PC petroleum consumption, NGC natural gas consumption, $\mathrm{CC}$ coal consumption, REC renewable energy consumption, CF capital formation, and LF labor force.

The energy efficiency data in this section is calculated by dividing GDP over total primary energy supply data obtained from IEA statistics. The renewable energy data is the sum up of all kinds of renewable energy. By the definition of IEA, renewable energy is divided into the three categories of: i) hydro fuel; ii) geothermal, solar, tide and wind fuel; and iii) combustible renewable energy and waste.

\section{Findings and analysis}

Results of Model 1 show that renewable energy variable has unexpected sign and does not significantly affect energy efficiency; this could be caused by such a multicollinearity with other variables. When the labor force is dropped from Model 1, as Model 2 shows renewable energy variable does affect energy efficiency. There is a positive relationship between renewable energy and energy efficiency. However, the renewable energy and GDP variables are still not statistically significant. Results of Model 3 show a better explanation of GDP, fossil fuel and renewable energy consumptions in relation with energy efficiency.

Table 5. Results of regressions of the contribution of renewable energy on energy efficiency using Partial-factor Energy Efficiency Model.

\begin{tabular}{|c|c|c|c|}
\hline \multicolumn{4}{|c|}{ Dependent Variable: Energy Efficiency (WDI) } \\
\hline Regressor & Model 1 & Model 2 & Model 3 \\
\hline Intercept & -1.527 & 0.845 & 1.304 \\
& $(1.986)$ & $(1.315)$ & $(1.231)$ \\
\hline \multirow{2}{*}{ Ln GDP } & 0.061 & 0.208 & $0.516^{* * *}$ \\
& $(0.334)$ & $(0.332)$ & $(0.117)$ \\
\hline Ln Petroleum consumption & $-0.414^{* * *}$ & $-0.325^{* *}$ & $-0.429^{* * *}$ \\
& $(0.143)$ & $(0.136)$ & $(0.087)$ \\
\hline \multirow{2}{*}{ Ln Natural gas consumption } & $0.145^{*}$ & $0.128^{*}$ & 0.078 \\
& $(0.069)$ & $(0.071)$ & $(0.050)$ \\
\hline \multirow{2}{*}{ Ln Coal consumption } & $-0.076^{* *}$ & $-0.061^{*}$ & $-0.066^{* *}$ \\
& $(0.030)$ & $(0.030)$ & $(0.029)$ \\
\hline \multirow{2}{*}{ Ln Renewable energy consumption } & -0.025 & 0.013 & 0.003 \\
& $(0.055)$ & $(0.051)$ & $(0.049)$ \\
\hline \multirow{2}{*}{ Ln Capital formation } & 0.168 & 0.104 & \\
\hline \multirow{2}{*}{ Ln Labor force } & $(0.109)$ & $(0.105)$ & \\
\hline Summary Statistics & 0.487 & & \\
\hline Adjusted R2 & $(0.314)$ & & \\
\hline F-statistic & 0.770 & 0.753 & 0.753 \\
\hline
\end{tabular}

Table 5. Continue in the next page 
Table 5. Results of regressions of the contribution of renewable energy on energy efficiency using Partial-factor Energy Efficiency Model (continue).

\begin{tabular}{|c|c|c|c|}
\hline \multicolumn{4}{|c|}{ Dependent Variable: Energy Efficiency (WDI) } \\
\hline Regressor & Model 1 & Model 2 & Model 3 \\
\hline DW-statistic & 2.3 & 1.811 & 1.779 \\
\hline
\end{tabular}

Remark: Standard errors are given in parentheses under the coefficients. The individual coefficient and F-statistic are statistically significant at the *10\%, **5\%, ***1\% significant level using a one-sided test.

In Model 3, both coefficients of petroleum (-0.429) and coal (- 0.066) consumptions have negative sign and significant at $1 \%$ and $5 \%$ level respectively. Thus, this means that for every increase in petroleum consumption by $1 \%$, Indonesia energy's efficiency will drop by $0.429 \%$, while, for every increase in domestic coal consumption, Indonesia's energy efficiency will decrease by $0.066 \%$, holding other independent variable constant. It is worth noting that the increase in petroleum and coal consumptions decreases Indonesia energy efficiency. In addition, other coefficients in Model 3, GDP, natural gas and renewable energy consumptions are having positive sign. It means that for every increase in those variables by $1 \%$, Indonesia's energy efficiency will increase by $0.516 \%, 0.078 \%$, and $0.003 \%$ respectively. Consequently, it is important for Indonesian economy not to increase petroleum and coal consumptions in order to improve its energy efficiency. In addition, it is recommended to substitute petroleum and coal as primary energy sources with renewable energy.

\section{Conclusion}

The challenges from the decreasing trend in energy efficiency must be addressed by the Government of Indonesia. Several policy options were proposed by scholars. The policy options are including the production and uses of renewable energy are expected to improve the energy efficiency and may enhance the economic performance.

This study was employing partial factor energy efficiency model to find the relationships between energy efficiency and renewable energy. On the other side, the model is also able to explore the connection between energy efficiency and consumption of nonrenewable energy.

The findings confirm the negative relationship between energy efficiency and consumption of non-renewable energy. However, the other finding revealed the positive impact of energy efficiency to the renewable energy. Those findings provide baselines to the Government of Indonesia to support the development of renewable energy and apply the policy to reduce the non-renewable energy consumption.

\section{References}

1. N. Syaifudin, A. Sutrisno, A.D. Setiawan. Energy Procedia 65, 239-247 (2015). https://www.sciencedirect.com/science/article/pii/S1876610215000387

2. D. Setyawan. Energy Procedia 47, 37-46 (2014). https://www.sciencedirect.com/science/article/pii/S1876610214002100

3. A. Rajbhandari, F. Zhang. Energy Economics. 128-139 (2018). https://www.sciencedirect.com/science/article/pii/S0140988317303882

4. J. Domac, K. Richards, S. Risovic. Biomass and Bioenergy, 28, 2:97-106 (2005). 
5. Direktorat Jenderal Energi Baru, Terbarukan dan Konservasi Energi. Buku statistik

EBTKE 2016 [Statistic book of new, renewable energy and energy conservation 2016].

Direktorat Jenderal Energi Baru, Terbarukan dan Konservasi Energi: Jakarta (2016). p.

viii. [in Bahasa Indonesia]

http://ebtke.esdm.go.id/post/2017/03/07/1583/statistik.ebtke.2016

6. Government of Indonesia. Government Regulation No. 79/2014 on National Energy

Policy [Peraturan Pemerintah No. 79/2014 tentang Kebijakan Energi Nasional] (2014).

7. T. Chien, J.L. Hu. Energy Policy, 35, 7:3606-3615 (2007). https://www.sciencedirect.com/science/article/pii/S0301421507000092

8. M. Krarti, F. Ali, A. Alaidroos, M. Houchati. International Journal of Sustainable Built Environment (2017). DOI: 10.1016/j.ijsbe.2017.12.006. https://www.sciencedirect.com/science/article/pii/S2212609017301061

9. I.E. Darwish, M Gomaa. Alexandria Engineering Journal, 56, 4:579-589 (2017). https://www.sciencedirect.com/science/article/pii/S1110016817301734

10. K. Li, B. Lin. Energy, 143, 812-821 (2018). https://www.sciencedirect.com/science/article/pii/S0360544217318960

11. G. Trotta. Energy Policy, 114, 529-539 (2018). https://www.sciencedirect.com/science/article/pii/S0301421517308686

12. R. Ahmed, M. Stater. Resource and Energy Economics, 49, 132-149, (2017). https://www.sciencedirect.com/science/article/pii/S0928765516300537

13. S. Wang, S. Wang. Energy, 140, 1:922-928 (2017). https://www.sciencedirect.com/science/article/pii/S0360544217315207

14. A. Çelen. Energy Policy 63, 300-310 (2013). https://www.sciencedirect.com/science/article/pii/S0301421513009580

15. The European Parliament. Understanding Energy Efficiency. Briefing October 2015 (2015)

http://www.europarl.europa.eu/RegData/etudes/BRIE/2015/568361/EPRS_BRI(2015)5 68361_EN.pdf (last accesed 17 February 2018).

16. H. Geller, P. Harrington, A.H. Rosenfeld, S. Tanishima, F. Unander. Energy Policy 34, 5:556-573 (2006).

https://www.sciencedirect.com/science/article/pii/S0301421505003113

17. M. Yang. Energy Policy 36, 2:561-570 (2008).

https://www.sciencedirect.com/science/article/pii/S0301421507004302

18. T. Wei. Energy Policy 35, 4:2023-2030 (2007).

https://www.sciencedirect.com/science/article/pii/S0301421506003272

19. J.L. Hu, C.H. Kao. Energy Policy 35, 1: 373-382 (2007).

https://www.sciencedirect.com/science/article/pii/S0301421505003290

20. P. Zhou, B.W. Ang. Energy Policy 36, 8:2911-2916 (2008).

https://www.sciencedirect.com/science/article/pii/S0301421508001638 